\title{
BAGAIMANA SUPERVISI AKADEMIK MENINGKATKAN KINERJA GURU SENIOR DAN JUNIOR
}

\author{
Rani Amrista Wijayanti \\ raniiamristaa@gmail.com
}

\begin{abstract}
This research aims to analyze the implementation of academic supervision conducted in one of private school in Bandar Lampung. It will examine whether the supervision is able to meet the challenges of the school in developing the teachers' performance and professionalism both senior and junior teachers. A private school which tends to experiences teachers' mutation and have new teachers will probably own more challenge to improve the achievement of the school. Teacher is considered to be the main factor to meet this challenge. Therefore, principal is highly expected to be responsible to monitor the teachers' performance. In this research, the writer aims to examine whether the supervision conducted has met the goal of the supervision. The result shows that the sustainable supervision has effectively conducted by the principal. The supervision was conducted with the following steps: planning, implementation, evaluation, and feedback and reporting. Based on the result score of the teachers 'supervision, it has been concluded that the supervision was conducted not only to fulfill the administrative duty of the principal but it can also fulfill the goal of supervision to monitor, guide and improve the teachers' performances. Besides, in this research, the writer concludes that sustainable supervision has been able to control the performance of both senior and junior teachers. Both the teachers show commitment and positive response to the implementation of supervision. The result shows that junior teachers have been equally developed as well as the senior teachers.
\end{abstract}

Key word: Supervision, performance, sustainable

\begin{abstract}
Abstrak
Penelitian ini bertujuan untuk menganalisis pelaksanaan kegiatan supervisi akademik dengan mengangkat permasalahan tantangan sekolah swasta meningkatkan kinerja guru baik guru senior maupunjunior.Sekolah swasta yang cenderung memiliki tingkat mutasi pergantian dan penambahan guru memiliki tantangan lebih, dalam menjaga mutu pendidikan di sekolah tersebut.Kepala sekolah memiliki tanggung jawab dalam memonitor dan meningkatkan kinerja guru dan tenaga pendidik.Oleh karena itu, supervisi akademik yang telah dilaksanakan perlu dianalisis apakah telah dilaksanakan secara efektif.Hasil analisis deskriptif menunjukkan bahwa supervisi akademik yang dilakukan secara kesinambungan telah terlaksana secara efektif. Kegiatan supervisi berlangsung sesuai dengan pedoman dalam Peraturan Menteri Pendidikan dan Kebudayaan Republik Indonesia Nomor 15 tahun 2018 yaitu melalui proses perencanaan, pelaksanaan, penilaian, tindak lanjut, dan pelaporan. Kegiatan supervisi ini dilaksanakan tidak hanya sekedar kewajiban administratif namun juga mampu memberikan pembinaan secara kesinambungan tersebut.Selain itu, penelitian ini mampu menjawab tantangan sekolah terkait pengontrolan kinerja guru senior dan guru junior.Hal ini dapat dilihat dari hasil skor supervisi akademik guru.Disimpulkan bahwa supervisi akademik yang didukung dengan sistem apresiasi kinerja guru yang jelas mampu meningkatkan semangat dan kinerja para guru dalam melaksanakan tugas dan meningkatkan profesionalitas. Guru senior dan junior sama-sama memiliki komitmen dan sikap positif terhadap supervisi akademik.
\end{abstract}

Kata kunci: Supervisi, kinerja, berkesinambungan 


\section{PENDAHULUAN}

Salah satu faktor penting dalam peningkatan mutu pendidikan di suatu sekolah adalah pelaksanaan pengawasan dan supervisi akademik (Agung dan Yufridawati, 2013).Supervisi akademik dinilai sebagai suatu bentuk pembinaan kepada guru dan tenaga pendidik dalam upaya mengembangkan profesionalisme, meningkatkan kinerja dan mencapai tujuan pembelajaran (Sudiyono \& Prasojo, 2011). Pelaksanaan supervisi akademik di sekolah diharapkan dapat dilakukan secara rutin oleh kepala sekolah karena supervisi merupakan salah satu tugas pokok Kepala Sekolah sebagaimana telah ditetapkan dalam Peraturan Menteri Pendidikan dan Kebudayaan (permendikbud) Republik Indonesia Nomor 6 Tahun 2018 dan Nomor 15 tahun 2018.

Kepala sekolah merupakan seorang guru yang mendapat tugas untuk memimpin dan mengelola satuan pendidikan (PermendikbudNo 15 tahun 2018). Dengan kata lain seorang kepala sekolah adalah tenaga pendidik yang memiliki wewenang dan tanggung jawab dalam memimpin dan mengembangkan sebuah sekolah agar kegiatan pembelajaran dapat terlaksana dengan baik. Kepala sekolah perlu melaksanakan supervisi secara profesional dengan berperdoman pada Peraturan Menteri Pendidikan dan Kebudayaan Republik Indonesia Nomor 15 tahun 2018. Kegiatan supervisi akademik harus dilakukan sesuai dengan rincian tugas yang telah ditetapkan yaitu berupa; (1) perencanaan program supervisi guru dan tenaga kependidikan; (2) pelaksanaan supervisi guru; (3) tindak lanjut hasil supervisi terhadap guru dalam rangka peningkatan profesionalisme guru; (4) evaluasi supervisi guru dan tenaga kependidikan; (5) pelaporan pelaksanaan tugas supervisi kepada guru dan tenaga kependidikan.

Pada kesempatan ini penulis mengambil sampel penelitian di sebuah sekolah swasta di Bandar Lampung, SMP Global Madani. Sekolah swasta yang baru menginjak usia 9 tahun ini baru saja mendapatkan akreditasi yang kedua kalinya dan memperoleh predikat A dengan nilai 96. Sebagai sekolah swasta, sekolah ini memiliki sebuah tantangan besar dalam menjaga kualitas pendidikan di sekolah tersebut agar dapat bersaing dengan sekolah lainnya.Dalam upaya tersebut, guru dianggap sebagai komponen utama dalam terciptanya pendidikan yang berkualitas.Hal ini sesuai dengan yang disampaikan oleh Widoyoko (2012) bahwa guru secara kesinambungan dituntut untuk mampu meningkatkan kinerjanya dengan menyelenggarakan kegiatan pembelajaran yang sesuai dengan kebutuhan dan visi sekolah tersebut.Kinerja guru tentunya akan dipantau dan dimonitor oleh pimpinan sekolah dalam hal ini kepala sekolah.

Selain itu, sekolah swasta juga memiliki tantangan lain terkait tingkat mutasi guru yang lebih tinggi dibanding sekolah negeri. Sekolah negeri pada umumnya memiliki guru tetap, dan Pegawai Negri Sipil (PNS),sedangkan sekolah swasta khususnya sekolah swasta baru lebih sering mengalami penambahan guru baru dan pergantian guru.Hal ini tentunya menjadi tantangan lebih bagi yayasan dan pimpinan sekolah untuk senantiasa mengontrol dan meningkatkan profesionalitas guru, khususnya guru baru atau guru junior. 
Oleh karena itu, berangkat dari identifikasi tantangan tersebut, ada beberapa pertanyaan yang akan dijawab dalam penelitian ini, yaitu: (1) Apakah kegiatan supervisi telah terlaksana secara efektif?(2) Apakah guru senior dan guru junior memiliki perbedaan hasil nilai supervisi yang signifikan? (3) Adakah faktor lain yang dapat mendukung terlaksananya supervisi akademik?

\section{METODE}

Penelitian ini memiliki tujuan untuk mendeskripsikan dan menganalisis program supervisi yang dilaksanakan di salah satu sekolah swasta di Bandar Lampung.Objek penelitian ini diambil secara natural langsung dari sumber data di sekolah dan melalui interaksi langsung sehingga penelitian ini menggunakan pendekatan kualitatif.

Subjek penelitian ini adalah guru yang bertugas di SMP Global Madani. Sampel guru yang diambil secara random adalah 10 guru junior (0-2 tahun pengalaman bekerja) dan 10 guru senior ( $\geq 2$ tahun pengalaman bekerja) dari total guru 34 orang di sekolah tersebut. Sampel yang diambil merupakan guru mata pelajaran yang beragam dan memiliki latar belakang pendidikan strata satudan magister pendidikan dari universitas yang beragam.

Dalam penelitian ini peneliti akan membedakan guru dalam dua tipe yaitu guru junior yangterdiri dari guru honorer dan calon guru tetap yayasan (CGTY), sedangkan guru senior adalah guru tetap yayasan (GTY).Pembagian tipe ini dibuat berdasarkan Standar Operasi Baku (SOP) Yayasan Pendidikan Global Madani bahwa guru dan tenaga kependidikan memiliki jenjang kepangkatan berupa guru honorer, calon guru tetap yayasan (CGTY), dan guru tetap yayasan (GTY).Guru honorer adalah guru yang memiliki pengalaman nol hingga satu tahun, guru CGTY adalah guru yang memiliki pengalaman lebih dari satu tahun dan GTY adalah guru yang memiliki pengalaman lebih dari 2 tahun.

Penelitian ini dilaksanakan melalui beberapa tahapan yaitu mengumpulkan dan mengolah data, dilanjutkan dengan menganalisis data dan menginterpretasi hasil temuan.

\section{HASIL DAN PEMBAHASAN}

SMP Global Madani memiliki sistem manajemen mutu dan pengelolaan yang profesional.Hal ini dapat dilihat dari sistem perekrutan guru, pengembangan guru dan program supervisi yang berkesinambungan.Perekrutan guru dilaksanakan dengan tahapan dan seleksi ketat yang dilaksanakan oleh pengelola yayasan dan para pimpinan (kepala sekolah dan wakil kepala sekolah).Sekolah ini juga melaksanakan program pengembangan profesional guru secara intens.Pengembangan profesional guru dilaksanakan secara rutin setiap pekan di hari Sabtu.Sekolah Pada hari tersebut siswa libur dan guru mengunakan kesempatan ini untuk program pengembangan diri berupa Musyawarah Guru Mata pelajaran (MGMP), belajar bahasa asing, pengajian rutin dan lain-lain. 
Program supervisi merupakan salah satu program pengembangan diri guru yang rutin dilaksanakan.Biasanya supervisi dilaksanakan oleh kepala sekolah dan dibantu oleh para wakil kepala sekolah.Pelaksanaan supervisi dilakukan dengan tahapan sebagai berikut:

1. Perencanaan: Program supervisi merupakan kegiatan rutin berkesinambungan. Kepala sekolah melakukan perencanaan dengan baik yaitu pembuatan jadwal supervisi, perumusan instrument, kemudian penjabaran, dan sosialisasi jadwal kepada guru dan tenaga kependidikan. Program ini dilaksanakan dua kali dalam setahun yaitu di semester ganjil dan semester genap. Adapun program ini tiap semesternya memiliki sedikit perbedaan dalam penentuan jadwal. Pada pelaksanaan supervisi di semester ganjil guru mendapatkan informasi waktu pelaksanaan sehingga guru mengetahui kapan akan disupervisi. Sedangkan pada pelaksanaan supervisi di semester genap, guru tidak diberi tahu jadwal pelaksanaannya sehingga guru dituntut untuk senantiasa siap kapanpun kepala sekolah mengadakan supervisi. Dalam penelitian ini, penulis mengambil data berdasarkan hasil supervisi di semester ganjil dimana para guru mendapat jadwal pelaksanaan supervisi.

2. Pelaksanaan: Supervisi pembelajaran di kelas dilaksanakan berdasarkan jadwal yang ditetapkan. Kepala sekolah menyupervisi kegiatan pembelajaran dimulai dari kegiatan pendahuluan, kegiatan inti, dan kegiatan penutup pembelajaran. Dalam pelaksanaan supervisi, kepala sekolah memantau seluruh komponen yang tertera dalam instrument berupa: (1) Kegiatan awal atau kegiatan pendahuluan; aspek yang dinilai adalah bagaimana guru menyiapkan peserta didik dengan penyampaian tujuan pembelajaran dan mampu mengaitkan materi pembelajaran dengan materi sebelumnya dengan cara memberikan pertanyaan yang menantang dan melalui apersepsi, (2) Kegiatan inti pembelajaran berupa penilaian komponen-komponen seperti bagaimana penerapan strategi pembelajaran yang mendidik, penerapan pendekatan scientific, pemanfaatan sumber belajar/media dalam pembelajaran, pelibatan peserta didik dalam pembelajaran dan penggunaan bahasa yang benar dan tepat dalam pembelajaran, (3) Kegiatan penutup yaitu penilaian bagaimana guru mampu memberikan refleksi pembelajaran hari tersebut dan memberikan tindak lanjut berupa pengarahan untuk kegiatan berikutnya.

Adapun instrument penilaian pelaksanaan pembelajaran di kelas dibuat berdasarkan format yang telah ditentukan oleh Dinas Pendidikan Kota Bandar Lampung, dalam hal ini kepala sekolah mendapatkan instrument dari pengawas pembina. Kemudian instrument tersebut dipadukan dengan beberapa komponen tambahan Sekolah Global Madani untuk mengukur pencapaian kurikulum unggulan sekolah seperti aspek penyampaian wawasan global, penggunaan media teknologi, dan penggunaan bahasa asing pembuka dan penutup serta bahasa instruksi dan lain-lain.

3. Pelaksanaan tindak lanjut hasil supervisi guru dilaksanakan setelah evaluasi dan penilaian supervisi dilakukan. Kemudian kegiatan tindak lanjut dilaksanankan dengan memberikan feedback kepada guru. Guru secara individu diberikan hasil penilaian berupa komplimen dan masukan. Kepala sekolah memberikan apresiasi atas pencapaian dan best practice 
yang diterapkan di dalam kelas kemudian memberikan saran untuk perbaikan ke depannya. Guru akan menerima rekapitulasi penilaian dan hasil pembinaan.

4. Hasil pembinaan tersebut akan dilaporkan kepada pengelola Yayasan Pendidikan Global Madani, dalam hal ini melalui Direktur Akademik dan Kesiswaan. Laporan tersebut menjadi salah satu rekam prestasi guru dan tenaga pendidik yang dapat digunakan sebagai bahan pertimbangan untuk promosi kenaikan pangkat dan reward atau tunjangan kinerja di yayasan seperti tunjangan Umroh, tunjangan Bintang Kesetiaan dsb.

Berikut adalah hasil skor penilaian supervisi akademik.

Tabel 1. Hasil Penilaian Supervisi Akademik

\begin{tabular}{|l|c|c|c|c|c|}
\hline Kategori & $\begin{array}{c}\text { Jumlah } \\
\text { guru }\end{array}$ & $\begin{array}{c}\text { Nilai } \\
\text { terendah }\end{array}$ & $\begin{array}{c}\text { Nilai } \\
\text { tertinggi }\end{array}$ & rata-rata & $\begin{array}{c}\text { Persentase guru } \\
\text { mendapat nilai } \\
\mathbf{8 6 - 1 0 0}\end{array}$ \\
\hline $\begin{array}{l}\text { Guru } \\
\text { junior }\end{array}$ & 10 & 74 & 92 & 80 & $60 \%$ \\
\hline $\begin{array}{l}\text { Guru } \\
\text { senior }\end{array}$ & 10 & 80 & 94 & 84 & $20 \%$ \\
\hline
\end{tabular}

Ketercapaian

$86-100=$ A (Amat baik)

$70-85=\mathrm{B}$ (Baik)

$56-69=\mathrm{C}($ Cukup $)$

$\leq 55=\mathrm{D}$ (Kurang)

Data pada tabel di atas menunjukkan bahwa skor terendah guru senior adalah 80 dengan predikat ketercapaian baik dan skor nilai tertinggi adalah 94 yaitu ketercapaian amat baik. Rata-rata skor guru adalah 84 (baik).

Sedangkan distribusi skor guru junior dengan nilai terendah adalah 74 dengan predikat ketercapaian baik dan dengan nilai tertinggi adalah 92(amat baik). Rata-rata skor guru adalah 80 (baik).

Dari hasil nilai rata-rata dapat diinterpretasikan bahwa perbandingan nilai guru senior dan juniortidak menunjukkan perbedaan yang signifikan. Rata-rata guru senior dan junior memperoleh nilai yang baik. Hal ini bisa terjadi karena beberapa faktor seperti adanya input guru yang cukup baik sehingga sebagian besar guru bahkan guru junior mampu mencapai nilai yang baik. Peneliti menilai bahwa hal ini kemungkinan disebabkan adanya sistem perekrutan guru yang ketat melalui proses yang cukup panjang. Proses perekrutan berupawalk in interview dan micro teaching dengan beberapa komponen penilaian yang cukup detail memberikan peluang mendapatkan input guru bagus cukup besar.

Analisis selanjutnya ditujukan pada persentase nilai guru yang mendapatkan skor amat baik.Tabel menunjukkan bahwa $60 \%$ guru senior mendapatkan nilai amat baik sedangkan 
40\% gurusisanya mendapat nilai dengan predikat baik. Adapun guru junior mampu mendapatkan nilai mendapatkan nilai maksimum dengan predikat amat baik adalah $20 \%$ dan $70 \%$ guru mendapat nilai predikat baik, sedangkan $10 \%$ sisanya mendapat hasil cukup baik.

Hasil persentasi skor nilaiamat baik guru senior dan junior yaitu $60 \%$ berbanding $20 \%$.Hal ini menunjukkan adanya perbedaan yang cukup signifikan antara skor guru senior dan junior.

Dari hasil tersebut, peneliti dapat menyimpulkan bahwa supervisi akademik yang berkesinambungan mampu meningkatkan kinerja guru. Hal ini ditunjukkan dengan perbandingan nilai guru senior yang cenderung tergolong tinggi dibandingkan dengan guru junior. Perbedaan tersebut bisa dikarenakan beberapa faktor seperti lamanya masa kerja yang artinya guru telah memiliki pengalaman dan pembinaan supervisi yang lebih intens. Dengan demikian dapat dikatakan bahwa supervisi berkelanjutan telah berjalan dengan efektif sesuai tujuan.

Kepala sekolah menambahkan pula bahwa supervisi akademik merupakan program yang sangat penting untuk dilaksanakan secara berkesinambungan karena supervisi menjadi salah satu bentuk penilaian kinerja guru dalam mengelola pembelajaran. Supervisi akademik membantu kepala sekolah dalam melaksanakan pembinaan dan menganalisa perkembangan guru, sehingga kepala sekolah dapat mengontrol dan memonitor perkembangan guru khususnya guru baru agar dapat meningkatkan kinerja.

Selain itu, peneliti juga menemukan hasil total keseluruhan guru senior dan junior adalah 19 guru (95\%) mendapatkan nilai di atas 70 dan hanya 5\% guru mendapat nilai di bawah 70 . Hal ini menunjukkan adanya sikap positif guru terhadap pelaksanaan supervisi akademik yang dilaksanakan oleh kepala sekolah.Kesimpulan ini penulis ambil berdasarkan penelitian yang disampaikan oleh Lambado (2015) bahwa guru yang memiliki sikap yang positif terhadap supervisi akademik cenderung memiliki persiapan yang matang sertakegiatan pembelajaran yang kreatif dan menarik.Sikap positif menjadi faktor pendukung yang mampu mengarahkan guru untuk berkomitmen melaksanakan tugas dengan baik selama supervisi akademik berlangsung.

Dapat disimpulkan bahwa sikap dan motivasi yang tinggi dalam pengembangan diri dan pencapaian hasil kerja yang maksimal demi memeroleh promosi kepegawaian dan reward dari yayasan dinilai sebagai faktor pendukung pelaksanaan supervisi akademik.

\section{KESIMPULAN}

Berdasarkan hasil pembahasan di atas dapat disimpulkan:

1. Supervisi akademik telah dilaksanakan bukan sekedar kewajiban administratif sekolah, namun kegiatan ini menjadi sebuah program pengembanganyang berkesinambungan dan dilaksanakan dengan efektif serta sesuai dengan ketetapan Permendiknas No 15 tahun 2018. 
2. Supervisi akademik yang berkesinambungan mampu meningkatkan kinerja guru. Hal ini dapat dilihat dari kecenderungan hasil skor supervisi guru senior yang berada pada kategori tinggi dibandingkan dengan hasil skor guru junior.

3. Adanya faktor pendukung sistem promosi kepegawaian dan reward dari yayasan telah mampu meningkatkan komitmen guru dan tenaga pendidik dalam pelaksanaan supervisi akademik. Baik guru senior dan junior memiliki komitmen dan sikap positif terhadap pelaksanaan supervisi. Ini dapat dilihat dari perolehanskor supervisi keseluruhan guru menunjukkan bahwa 95\% guru senior dan juniormampu mendapatkan nilai yang baik.

\section{DAFTAR PUSTAKA}

Aco, Lambado. 2015. Evaluasi Efektifitas Pelaksanaan SUpervisi Pembelajaran, Jurnal Himpunan Evaluasi Pendidikan Indonesia (HEPI): 422-432.

Agung, Iskandar \& Yufridawati.(2013). Pengembangan Pola Kerja Harmonis dan Sinergis antara Guru, Kepala Sekolah \& Pengawas. Jakarta: PT Bestari Buana Murni.

Peraturan Menteri Pendidikan Nasional Republik Indonesia Nomor 6 tahun 2018 tentang Penugasan Guru Sebagai Kepala Sekolah

Peraturan Menteri Pendidikan Nasional Republik Indonesia Nomor 6 tahun 2018 tentang Pemenuhan Beban Kerja Guru, Kepala Sekolah, dan Pengawas Sekolah.

Sudiyono \& Prasojo, L.D. (2011). Supervisi Pendidikan. Yogyakarta: Gava Media.

Surdin, Ali. (2008). Implementasi Supervisi Akademik Terhadap Proses Pembelajaran di Sekolah Dasar se Kabupaten SUmedang, Jurnal, Pendidikan Dasar no:9- April 2008.

Widoyoko, S. Eko Putro. (2012) Teknik Penyusunan Instrumen Penelitian. Yogyakarta: Pustaka Pelajar. 